\title{
Pharmacist counseling in a cohort of women with HIV and women at risk for HIV
}

This article was published in the following Dove Press journal:

Patient Preference and Adherence

16 June 2012

Number of times this article has been viewed

Jennifer M Cocohoba'

Keri N Althoff ${ }^{2}$

Mardge Cohen ${ }^{3}$

Haihong $\mathrm{Hu}^{4}$

Chinazo $O$ Cunningham ${ }^{5}$

Anjali Sharma ${ }^{6}$

Ruth M Greenblatt ${ }^{1,7}$

'University of California, San Francisco School of Pharmacy, San Francisco, CA; ${ }^{2}$ Johns Hopkins Bloomberg School of Public Health, Baltimore, MD; ${ }^{3}$ Department of Medicine, Stroger Hospital and Rush Medical College, Chicago, IL; ${ }^{4}$ Department of Medicine, Georgetown University, Washington, DC; ${ }^{5}$ Albert Einstein College of Medicine, Bronx, NY; ${ }^{6}$ SUNY Downstate Medical Center, Brooklyn, NY; ${ }^{7}$ University of California, San Francisco School of Medicine, San Francisco, CA, USA
Correspondence: Jennifer M Cocohoba Department of Clinical Pharmacy, University of California, San Francisco School of Pharmacy, 52I Parnassus Avenue, C-152, Box 0622, San Francisco, CA 94143-0622, USA

Tel + I 4I5 5I40892

Fax +I 4154766632

Email cocohobaj@pharmacy.ucsf.edu
Background and methods: Achieving high adherence to antiretroviral therapy for human immunodeficiency virus (HIV) is challenging due to various system-related, medication-related, and patient-related factors. Community pharmacists can help patients resolve many medicationrelated issues that lead to poor adherence. The purpose of this cross-sectional survey nested within the Women's Interagency HIV Study was to describe characteristics of women who had received pharmacist medication counseling within the previous 6 months. The secondary objective was to determine whether HIV-positive women who received pharmacist counseling had better treatment outcomes, including self-reported adherence, CD4 ${ }^{+}$cell counts, and HIV-1 viral loads.

Results: Of the 783 eligible participants in the Women's Interagency HIV Study who completed the survey, only $30 \%$ of participants reported receiving pharmacist counseling within the last 6 months. Factors independently associated with counseling included increased age (odds ratio [OR] 1.28; 95\% confidence interval [CI] 1.07-1.55), depression (OR 1.75; 95\% CI 1.25-2.45), and use of multiple pharmacies (OR 1.65; 95\% CI 1.15-2.37). Patients with higher educational attainment were less likely to report pharmacist counseling (OR 0.68; 95\% CI 0.48-0.98), while HIV status did not play a statistically significant role. HIV-positive participants who received pharmacist counseling were more likely to have optimal adherence (OR 1.23; 95\% CI 0.70-2.18) and increased $\mathrm{CD}^{+}$cell counts ( +43 cells $/ \mathrm{mm}^{3}, 95 \%$ CI 17.7-104.3) compared with those who had not received counseling, though these estimates did not achieve statistical significance.

Conclusion: Pharmacist medication counseling rates are suboptimal in HIV-positive and at-risk women. Pharmacist counseling is an underutilized resource which may contribute to improved adherence and $\mathrm{CD} 4^{+}$counts, though prospective studies should be conducted to explore this effect further.

Keywords: human immunodeficiency virus, acquired immunodeficiency syndrome, antiretroviral therapy, community pharmacy, pharmacy practice, women's health

\section{Introduction}

Human immunodeficiency virus (HIV) has joined the suite of chronic diseases controlled by long-term medication. Patients who initiate antiretroviral therapy have significantly reduced morbidity and mortality, yet long-term adherence to multicomponent antiretroviral regimens can be challenging, and is typically suboptimal. ${ }^{1-3}$ Barriers to adherence can arise via health systems, such as with complex insurance systems, delayed refills due to multilevel communication, or medication errors. Factors related to antiretroviral therapy, such as pill size and adverse effects, also affect adherence. Lastly, there are a host of patient-level barriers to antiretroviral therapy adherence, including the stigma associated with HIV disease and taking medication, comorbidities such 
as depression or substance abuse, economic hardships that impair obtaining antiretroviral therapy, busy life schedules, lack of understanding about the medications or the importance of adherence, forgetting, and poor motivation. ${ }^{4-6}$

Patients may seek assistance from their HIV clinicians, but clinicians are often hard pressed for time, or may lack the skill or confidence to address adherence problems. ${ }^{7-9}$ In an era of expanding medication treatment and decreasing medical provider time, community pharmacists can serve as an important resource for HIV-positive patients and their clinicians. Pharmacists are easily accessible and are trained to help patients solve various medication-related problems that can impair adherence ${ }^{10,11}$ They can provide helpful education on HIV treatment, engage in adherence counseling. They can provide helpful education on HIV treatment, engage in adherence counseling when underutilization is detected, provide medication reminder devices to minimize forgetting, share self-care strategies for mild to moderate side effects, advocate on behalf of a patient experiencing troublesome insurance issues, and link patients to programs to help decrease medication costs. ${ }^{10,12,13}$ By advocating for patients in these and in various other ways, pharmacists can help patients adhere better to their medications.

Pharmacists have the potential to be effective HIV treatment advocates, but it is unclear to what extent HIV-positive patients actually utilize their pharmacists as a resource. The purpose of this study is to look within a cohort of women who are HIV-positive or at risk for HIV infection, to determine the proportion that consult with their community pharmacists, and explore factors associated with receiving pharmacist medication counseling. The secondary objective is to determine whether the subset of HIV-positive women who received pharmacist counseling have better treatment outcomes, including higher self-reported adherence, higher CD4 ${ }^{+}$cell counts, and suppressed HIV-1 viral loads compared with HIV-positive women who do not.

\section{Methods}

\section{Study population}

We performed a cross-sectional study nested within the Women's Interagency HIV Study (WIHS). The WIHS is the largest prospective, observational cohort study of the natural and treated history of HIV in women in the US. Women in WIHS were enrolled at six sites including Bronx, NY, Brooklyn, NY, Baltimore, MD, Washington DC, Chicago, IL, San Francisco, CA, and Los Angeles, CA, during two recruitment waves in 1994-1995 ( $\mathrm{n}=2625$ women) and 2001-2002 ( $n=1143$ women). Characteristics of WIHS participants have been described in previous studies. ${ }^{14,15}$ Participants in WIHS undergo semiannual study visits during which an extensive interview is administered. Inquiries about sociodemographic characteristics, medical care, health status, mental and behavior health issues, and medication use are conducted. Participants have the option of bringing their medications to the study visits to aid identification. A clinical examination and blood drawn for laboratory testing is also performed at each study visit. Study protocols and consent forms have been approved by institutional review boards at each study site.

At visit 27 (October 2007 to April 2008), WIHS participants at five study sites (San Francisco, Chicago, Bronx, Brooklyn, Washington DC, Baltimore) were given a 51-item self-administered questionnaire (ie, in a pharmacy experiences substudy) to assess pharmacy characteristics and utilization, medication-related expenses, participation in adherence programs, and experience with medication errors, missing medications, and privacy violations at the pharmacy. Participants were eligible for the pharmacy experiences substudy if they self-reported taking any prescription medication for more than 10 days out of each month since the last study visit.

\section{Statistical analysis}

The primary outcome of interest for this study was a WIHS participant's self-reported receipt of any community pharmacist counseling (yes/no) within the 6 months prior to their study visit (visit 27). Secondary outcomes included antiretroviral therapy adherence (self-reported as either $<75 \%$, $75 \%-94 \%, 95 \%-99 \%$, or $100 \%$ of antiretroviral therapy doses taken as prescribed, over the last 6 months), and WIHS-measured CD4+ cell counts and HIV viral load. CD4 ${ }^{+}$ count and viral load were measured in laboratories which participate in National Institutes of Health/National Institute of Allergies and Infectious Diseases quality assurance programs during the same visit the pharmacy experiences substudy questionnaire was completed.

Additional covariates of interest were identified. Race was measured by self-report upon initial WIHS enrollment. Participants' self-reported highest educational attainment, annual household income, employment status, drug and alcohol use in the last 6 months, health insurance, presence of severe depressive symptoms (using the Center for Epidemiologic Studies Depression score $\geq 16$ ), and antiretroviral therapy use were measured at visit 27. A participant was categorized as having acquired immunodeficiency syndrome (AIDS) if she had ever self-reported a clinical AIDS diagnosis. 
Table 2 Factors associated with receiving pharmacist medication counseling

\begin{tabular}{|c|c|c|}
\hline Characteristic & $\begin{array}{l}\text { Univariate OR } \\
(95 \% \mathrm{Cl})\end{array}$ & $\begin{array}{l}\text { Adjusted OR } \\
(95 \% \mathrm{Cl})\end{array}$ \\
\hline HIV-positive & $0.87(0.59-1.28)$ & $0.90(0.59-1.36)$ \\
\hline Age, per 10 years & $1.38(1.16-1.65)^{*}$ & $1.28(1.07-1.55)^{*}$ \\
\hline \multicolumn{3}{|l|}{ Race } \\
\hline Caucasian & Ref & - \\
\hline African American & $0.81(0.55-1.19)$ & - \\
\hline Other & $0.89(0.52-I .5 I)$ & - \\
\hline $\begin{array}{l}\text { Annual household } \\
\text { income }>\$ 30,000, \mathrm{n}(\%)\end{array}$ & $\mathrm{I} .00(0.7 \mathrm{I}-\mathrm{I} .43)$ & - \\
\hline Has insurance, $n(\%)$ & $1.59(0.78-3.25)$ & $1.16(0.53-2.50)$ \\
\hline Finished high school & $0.72(0.52-1.01)$ & $0.68(0.48-0.98)^{*}$ \\
\hline Center for Epidemiologic & $1.91(1.39-2.62)^{*}$ & $1.75(1.25-2.45)^{*}$ \\
\hline \multicolumn{3}{|l|}{ Studies Depression score $>15$} \\
\hline Drug use in the last 6 months & $\mathrm{I} .43(0.99-2.07)$ & $\mathrm{I} .15(0.77-1.72)$ \\
\hline \multicolumn{3}{|l|}{ Alcohol use over the last 6 months } \\
\hline$<3$ drinks/week & Ref & - \\
\hline 3-13 drinks/week & $1.16(0.68-1.97)$ & - \\
\hline$>13$ drinks/week & $0.97(0.37-2.53)$ & - \\
\hline $\begin{array}{l}\text { Uses chain pharmacy as } \\
\text { primary pharmacy }\end{array}$ & $0.68(0.44-1.06)$ & $0.63(0.39-1.02)$ \\
\hline Uses more than one pharmacy & $1.86(1.3 \mathrm{I}-2.63)^{*}$ & $1.65(1.15-2.37)^{*}$ \\
\hline Uses a pharmacy more than & $\mathrm{I} .45(0.76-2.74)$ & - \\
\hline \multicolumn{3}{|l|}{20 miles away } \\
\hline \multicolumn{3}{|l|}{ WIHS study site } \\
\hline Bronx & Ref & Ref \\
\hline Brooklyn & $\mathrm{I} .06(0.62-1.8 \mathrm{I})$ & I.0I (0.58-I.77) \\
\hline Washington DC & $0.71(0.36-1.38)$ & $0.69(0.34-1.38)$ \\
\hline San Francisco Bay Area & $1.81(1.06-3.11)^{*}$ & $1.51(0.85-2.70)$ \\
\hline Chicago & $0.92(0.5 \mathrm{I}-1.68)$ & $0.84(0.45-1.59)$ \\
\hline
\end{tabular}

Note:*Statistically significant.

Abbreviations: OR, odds ratio; $\mathrm{Cl}$, confidence interval; HIV, human immunodeficiency virus; WIHS, Women's Interagency HIV Study.

model, older participants and those who received pharmacist counseling had a higher odds of having optimal self-reported adherence, though the association for pharmacist counseling did not reach statistical significance (OR 1.23, 95\% CI 0.70-2.18). As expected, depression, drug or alcohol use, having AIDS, and taking a protease inhibitor-based regimen were negatively associated with optimal adherence (Table 3). In unadjusted analyses, speaking with a pharmacist was associated with a $43 \mathrm{cell} / \mathrm{mm}^{3}$ higher $\mathrm{CD}^{+}$cell count compared with those who did not talk with the pharmacist $(95 \% \mathrm{CI}$ $17.7-104.3, P=0.16)$. This association accounted for less than $1 \%$ of the variability in $\mathrm{CD}^{+}$cell counts. The point estimate for the association between speaking with a pharmacist and having an undetectable viral load in our sample suggested no effect (OR 0.99, 95\% CI 0.64-1.52, $P=0.96$ ).

\section{Discussion}

Our study offers a brief look at community pharmacist counseling in a cohort of women with HIV and women
Table 3 Factors associated with self-reported antiretroviral adherence $\geq 95 \%$ amongst HIV-positive participants

\begin{tabular}{|c|c|c|}
\hline & $\begin{array}{l}\text { Univariate OR } \\
(95 \% \mathrm{Cl})\end{array}$ & $\begin{array}{l}\text { Adjusted OR } \\
(95 \% \mathrm{Cl})\end{array}$ \\
\hline Age (per 10 years) & $1.29(0.99-1.69)$ & $1.54(1.13-2.10)^{*}$ \\
\hline Having health insurance & $1.20(0.39-3.69)$ & $1.01(0.28-3.66)$ \\
\hline Completed high school & $0.74(0.46-1.18)$ & $0.83(0.50-1.38)$ \\
\hline Depression (CESD > I5) & $0.42(0.27-0.67)^{*}$ & $0.50(0.3 \mathrm{I}-0.83)^{*}$ \\
\hline $\begin{array}{l}\text { Drug or heavy alcohol } \\
\text { (>13 drinks/week) } \\
\text { use in last } 6 \text { months }\end{array}$ & $0.42(0.24-0.7 \mathrm{I}) *$ & $0.46(0.25-0.82)^{*}$ \\
\hline Having AIDS & $0.46(0.28-0.73)^{*}$ & $0.45(0.27-0.75)^{*}$ \\
\hline $\begin{array}{l}\text { Number of years since started } \\
\text { antiretroviral therapy }\end{array}$ & $1.00(0.93-1.07)$ & - \\
\hline $\begin{array}{l}\text { Using chain drugstore as } \\
\text { primary pharmacy }\end{array}$ & $0.77(0.43-1.38)$ & $0.77(0.4 I-I .45)$ \\
\hline $\begin{array}{l}\text { Picking up own medicines } \\
\text { from pharmacy }\end{array}$ & $0.86(0.44-1.67)$ & - \\
\hline Using more than one pharmacy & $0.81(0.48-1.36)$ & - \\
\hline Regimen type & & \\
\hline NNRTI-based & Ref & Ref \\
\hline PI-based & $0.39(0.22-0.70) *$ & $0.40(0.22-0.73)^{*}$ \\
\hline Other & $0.54(0.25-1.19)$ & $0.5 I(0.23-1.16)$ \\
\hline $\begin{array}{l}\text { Spoke with the pharmacist } \\
\text { in the last } 6 \text { months }\end{array}$ & $1.13(0.67-1.90)$ & $1.23(0.70-2.18)$ \\
\hline
\end{tabular}

Note:*Statistically significant.

Abbreviations: AIDS, acquired immunodeficiency syndrome; OR, odds ratio; $\mathrm{Cl}$, confidence interval; CESD, Center for Epidemiological Studies Depression Score; NNRTI, nonnucleoside reverse transcriptase inhibitor; PI, protease inhibitor.

with high-risk HIV behaviors. Only a modest proportion of study participants (30\%) self-reported receipt of pharmacist counseling in the past 6 months. Recall bias may have underestimated the true proportion of participants who received counseling. Another explanation is that pharmacists may be missing valuable opportunities to detect and intervene on patient adherence and medication problems. The low proportion of participants reporting counseling in our study could be reflective of the WIHS population. Female gender has been associated with underutilization of HIV health care services and this may also be true of HIV pharmacy services. ${ }^{16-18} \mathrm{HIV}$-positive patients may be less likely to seek pharmacist counseling due to concerns about privacy around HIV medications; however, the proportions of HIV-positive and HIV-negative participants reporting pharmacist counseling in our study were similar. ${ }^{19}$ Given that pharmacists are a vast potential resource for adherence support, it is important to understand the reasons why participants may not communicate with their pharmacists. These reasons cannot be fully elucidated by our retrospective, survey-based study design and should be further explored in qualitative studies with both patients and pharmacists.

HIV-infected women who did report pharmacist counseling in the past 6 months also reported higher antiretroviral 
therapy adherence and increased $\mathrm{CD}^{+}$cell counts compared with those who had not. These observed associations were small, but positive. Though the point estimates did not achieve statistical significance, our findings are consistent with other studies which found that HIV pharmacists in ambulatory care and inpatient settings had a positive impact on $\mathrm{CD}^{+}$cell counts and improving antiretroviral adherence, in addition to achieving undetectable HIV viral loads, adjusting for drug interactions, and lowering numbers of office visits. $^{20-32,37}$

Despite their efforts to improve the health of patients with chronic diseases, the work of community pharmacists in HIV may be underappreciated, and is less frequently described in the literature. Three papers described a pilot program of 10 California community pharmacies that received funding to provide medication therapy management services for HIVpositive patients. ${ }^{13,33,34}$ Services offered in these 10 pharmacies varied greatly; they included adherence enhancements such as refill reminders, reminder packaging, and specialized antiretroviral medication counseling. ${ }^{13}$ At 3 years, HIV-positive patients filling their antiretroviral therapy at the pilot pharmacies $(n=2234)$ demonstrated higher refill adherence (medication possession ratios $69.4 \%$ versus $47.3 \%$, $P<0.001$ ), and a higher odds of having optimal adherence (OR 2.74, 95\% CI 2.44-3.10, after controlling for age, gender, and ethnicity) compared with traditional pharmacies. ${ }^{33,34}$ These pilot programs represent the ideal end of the spectrum of HIV community pharmacy care. Many other community pharmacists might hope to provide this type of high level care for their HIV-positive patients, but may be unable to do so for lack of funding, time, support, or expertise. ${ }^{35}$

Our study reveals minimal engagement in the potentially beneficial relationship between HIV-positive women and their community pharmacists. This information in itself is valuable, but also speaks to the continued research that needs to be done to understand HIV patient-pharmacist relationships better, the impact of community pharmacy care, and how to optimize elements of HIV pharmacy care to have maximal clinical and adherence impact. It can be challenging to operationalize research on pharmacists' day-to-day practice, yet conducting these types of studies is important to substantiate the benefits of pharmacist counseling on outcomes for HIV and other chronic diseases. With further studies quantifying the health benefits added by the intense participation of community pharmacists on the HIV health care team, funding and support may be made more readily available, and HIV pharmacist services may be made more accessible to all patients. ${ }^{24,36}$
There are various limitations associated with our study. Our study required participants to self-identify whether or not they had received pharmacist counseling. This could have been subject to recall bias or lack of identification of counseling within an encounter, underestimating the overall penetration of pharmacist counseling. Study participants were already highly adherent to their antiretroviral therapy regimens, leaving minimal room for improvement for any intervention. Participants utilized different pharmacies that may represent very diverse models of HIV pharmacy care. A standardized pharmacist counseling intervention developed in collaboration with local HIV clinics may have a clearer impact on clinical and adherence outcomes for HIV-positive persons. Lastly, confounding by indication could have masked some positive effects of counseling. Patients who appeared to be struggling with adherence (and subsequently having lower $\mathrm{CD} 4{ }^{+}$cell counts and increased viral loads) could have been more likely to receive counseling from their pharmacists. If poor adherence prompted pharmacist counseling, this could cause counseling to appear to perform poorly, even if it truly is effective in improving adherence.

\section{Conclusion}

Counseling and treatment advocacy by community pharmacists is an underutilized health care resource that has the potential to improve the health of patients with HIV. Our study found a small, positive association between speaking with the pharmacist in the last 6 months and having higher adherence or $\mathrm{CD}^{+}$cell counts that did not achieve statistical significance. Limitations of our study include possible confounding by indication that could have masked some benefit of counseling and a population of study participants who were already highly adherent to their antiretrovirals. Given the shrinking availability of health care resources today, efforts to develop community pharmacy HIV programs should be coordinated with local clinics to provide the most efficient services, and prospective studies which test the efficacy and impact of these programs should continue to be explored.

\section{Acknowledgments}

This research was supported by the National Institutes for Mental Health (JMC, K23MH087218) and the Building Interdisciplinary Research Careers in Women's Health Program (K12HD052163). Data in this manuscript were collected by the WIHS Collaborative Study Group with centers (principal investigators) at New York City/Bronx Consortium (Kathryn Anastos); Brooklyn, NY (Howard Minkoff); Washington DC, Metropolitan Consortium (Mary 
Young); The Connie Wofsy Study Consortium of Northern California (Ruth Greenblatt); Los Angeles County/Southern California Consortium (Alexandra Levine); Chicago Consortium (Mardge Cohen); and Data Coordinating Center (Stephen Gange). The WIHS is funded by the National Institute of Allergy and Infectious Diseases (UO1-AI-35004, UO1-AI-31834, UO1-AI-34994, UO1-AI-34989, UO1AI-34993, and UO1-AI-42590) and by the Eunice Kennedy Shriver National Institute of Child Health and Human Development (UO1-HD-32632). The study is cofunded by the National Cancer Institute, the National Institute on Drug Abuse, and the National Institute on Deafness and Other Communication Disorders. Funding is also provided by the National Center for Research Resources (UCSF-CTSI grant number UL1 RR024131). The contents of this publication are solely the responsibility of the authors and do not necessarily represent the official views of the National Institutes of Health. The authors would like to acknowledge Peter Bacchetti and Mallory Johnson for their contributions to the guidance of statistical analysis and manuscript writing for this study.

\section{Disclosure}

Data from this study were shown as part of a poster presentation at the American College of Clinical Pharmacy Annual Meeting, October 5, 2009, San Antonio, TX.

\section{References}

1. Palella FJ Jr, Delaney KM, Moorman AC, et al. Declining morbidity and mortality among patients with advanced human immunodeficiency virus infection. HIV Outpatient Study Investigators. $N$ Engl $J$ Med. 1998;338(13):853-860.

2. Palella FJ Jr, Deloria-Knoll M, Chmiel JS, et al; HIV Outpatient Study Investigators. Survival benefit of initiating antiretroviral therapy in HIV-infected persons in different CD4+ cell strata. Ann Intern Med. 2003;138(8):620-626.

3. Sabate E. Adherence to long-term therapies: evidence for action, 2003. Available from: http://whqlibdoc.who.int/publications/2003/9241545992. pdf. Accessed June 16, 2008.

4. Ammassari A, Murri R, Pezzotti P, et al. Self-reported symptoms and medication side effects influence adherence to highly active antiretroviral therapy in persons with HIV infection. J Acquir Immune Defic Syndr. 2001;28(5):445-449.

5. Johnson MO, Charlebois E, Morin SF, et al. Perceived adverse effects of antiretroviral therapy. J Pain Symptom Manage. 2005;29(2): 193-205.

6. Remien RH, Hirky AE, Johnson MO, Weinhardt LS, Whittier D, Le GM. Adherence to medication treatment: a qualitative study of facilitators and barriers among a diverse sample of HIV+ men and women in four US cities. AIDS Behav. 2003;7(1):61-72.

7. Barfod TS, Hecht FM, Rubow C, Gerstoft J. Physicians' communication with patients about adherence to HIV medication in San Francisco and Copenhagen: a qualitative study using grounded theory. BMC Health Serv Res. 2006;6:154.
8. Laws MB, Beach MC, Lee Y, et al. Provider-patient adherence dialogue in HIV care: results of a multisite study. AIDS Behav. January 31, 2012. [Epub ahead of print.]

9. Wilson IB, Laws MB, Safren SA, et al. Provider-focused intervention increases adherence-related dialogue but does not improve antiretroviral therapy adherence in persons with HIV. J Acquir Immune Defic Syndr. 2010;53(3):338-347.

10. Barnett MJ, Frank J, Wehring H, et al. Analysis of pharmacist-provided medication therapy management (MTM) services in community pharmacies over 7 years. J Manag Care Pharm. 2009;15(1):18-31.

11. D'Antonio N. Including motivational interviewing skills in the PharmD curriculum. Am J Pharm Educ. 2010;74(8):152d.

12. Ahmad A, Hugtenburg J, Welschen LM, Dekker JM, Nijpels G. Effect of medication review and cognitive behaviour treatment by community pharmacists of patients discharged from the hospital on drug related problems and compliance: design of a randomized controlled trial. $B M C$ Public Health. 2010;10:133.

13. Rosenquist A, Best BM, Miller TA, Gilmer TP, Hirsch JD. Medication therapy management services in community pharmacy: a pilot programme in HIV specialty pharmacies. JEval Clin Pract. 2010;16(6): $1142-1146$.

14. Bacon MC, von Wyl V, Alden C, et al. The Women's Interagency HIV Study: an observational cohort brings clinical sciences to the bench. Clin Diagn Lab Immunol. 2005;12(9):1013-1019.

15. Barkan SE, Melnick SL, Preston-Martin S, et al. The Women's Interagency HIV Study. WIHS Collaborative Study Group. Epidemiology. 1998; 9(2):117-125.

16. Gebo KA, Fleishman JA, Conviser R, et al. Racial and gender disparities in receipt of highly active antiretroviral therapy persist in a multistate sample of HIV patients in 2001. J Acquir Immune Defic Syndr. 2005;38(1):96-103.

17. Puskas CM, Forrest JI, Parashar S, et al. Women and vulnerability to HAART non-adherence: a literature review of treatment adherence by gender from 2000 to 2011. Curr HIV/AIDS Rep. 2011;8(4): 277-287.

18. Sohler NL, Li X, Cunningham CO. Gender disparities in HIV health care utilization among the severely disadvantaged: can we determine the reasons? AIDS Patient Care STDS. 2009;23(9):775-783.

19. Sayles JN, Wong MD, Cunningham WE. The inability to take medications openly at home: does it help explain gender disparities in HAART use? J Womens Health (Larchmt). 2006;15(2):173-181.

20. Bozek PS, Perdue BE, Bar-Din M, Weidle PJ. Effect of pharmacist interventions on medication use and cost in hospitalized patients with or without HIV infection. Am J Health Syst Pharm. 1998;55(11):1151-1155.

21. Castillo E, Palepu A, Beardsell A, et al. Outpatient pharmacy care and HIV viral load response among patients on HAART. AIDS Care. 2004;16(4):446-457.

22. de Maat MM, de Boer A, Koks CH, et al. Evaluation of clinical pharmacist interventions on drug interactions in outpatient pharmaceutical HIV care. J Clin Pharm Ther. 2004;29(2):121-130.

23. Frick P, Tapia K, Grant P, Novotny M, Kerzee J. The effect of a multidisciplinary program on HAART adherence. AIDS Patient Care STDS. 2006;20(7):511-524.

24. Horberg MA, Hurley LB, Silverberg MJ, Kinsman CJ, Quesenberry CP. Effect of clinical pharmacists on utilization of and clinical response to antiretroviral therapy. J Acquir Immune Defic Syndr. 2007; 44(5):531-539.

25. Krummenacher I, Cavassini M, Bugnon O, Schneider MP. An interdisciplinary HIV-adherence program combining motivational interviewing and electronic antiretroviral drug monitoring. AIDS Care. 2011;23(5):550-561.

26. Krummenacher I, Cavassini M, Bugnon O, Spirig R, Schneider MP; Swiss HIV Cohort Study. Antiretroviral adherence program in HIV patients: a feasibility study in the Swiss HIV Cohort Study. Pharm World Sci. 2010;32(6):776-786. 
27. Levy RW, Rayner CR, Fairley CK, et al. Multidisciplinary HIV adherence intervention: a randomized study. AIDS Patient Care STDS. 2004;18(12):728-735.

28. Ma A, Chen DM, Chau FM, Saberi P. Improving adherence and clinical outcomes through an HIV pharmacist's interventions. AIDS Care. 2010;22(10):1189-1194.

29. McPherson-Baker S, Malow RM, Penedo F, Jones DL, Schneiderman N, Klimas NG. Enhancing adherence to combination antiretroviral therapy in non-adherent HIV-positive men. AIDS Care. 2000;12(4):399-404.

30. Ostrop NJ, Gill MJ. Antiretroviral medication adherence and persistence with respect to adherence tool usage. AIDS Patient Care STDS. 2000;14(7):351-358.

31. Rathbun RC, Farmer KC, Stephens JR, Lockhart SM. Impact of an adherence clinic on behavioral outcomes and virologic response in the treatment of HIV infection: A prospective, randomized, controlled pilot study. Clin Ther. 2005;27(2):199-209.

32. Smith SR, Rublein JC, Marcus C, Brock TP, Chesney MA. A medication self-management program to improve adherence to HIV therapy regimens. Patient Educ Couns. 2003;50(2):187-199.
33. Hirsch JD, Gonzales M, Rosenquist A, Miller TA, Gilmer TP, Best BM Antiretroviral therapy adherence, medication use, and health care costs during 3 years of a community pharmacy medication therapy management program for Medi-Cal beneficiaries with HIV/AIDS. J Manag Care Pharm. 2011;17(3):213-223.

34. Hirsch JD, Rosenquist A, Best BM, Miller TA, Gilmer TP. Evaluation of the first year of a pilot program in community pharmacy: HIV/AIDS medication therapy management for Medi-Cal beneficiaries. J Manag Care Pharm. 2009;15(1):32-41.

35. Smith SR, Golin CE, Reif S. Influence of time stress and other variables on counseling by pharmacists about antiretroviral medications. Am J Health Syst Pharm. 2004;61(11):1120-1129.

36. Horberg MA, Bartemeier Hurley L, James Towner W, et al. Determination of optimized multidisciplinary care team for maximal antiretroviral therapy adherence. JAcquir Immune Defic Syndr. March 19, 2012. [Epub ahead of print.]

37. March K, Mak M, Louie SG. Effects of pharmacists' interventions on patient outcomes in an HIV primary care clinic. Am J Health Syst Pharm. 2007;64(24):2574-2578.
Patient Preference and Adherence

\section{Publish your work in this journal}

Patient Preference and Adherence is an international, peer-reviewed, open access journal focusing on the growing importance of patient preference and adherence throughout the therapeutic continuum. Patient satisfaction, acceptability, quality of life, compliance, persistence and their role in developing new therapeutic modalities and compounds to

\section{Dovepress}

optimize clinical outcomes for existing disease states are major areas of interest. This journal has been accepted for indexing on PubMed Central. The manuscript management system is completely online and includes a very quick and fair peer-review system. Visit http://www.dovepress.com/ testimonials.php to read real quotes from published authors.

Submit your manuscript here: http://www.dovepress.com/patient-preference-and-adherence-journal 